\title{
Curbing the Cultural Practices of Wife Inheritance and Polygamy through Information Dissemnation in Benue State
}

\author{
Ashaver Doosuur ${ }^{1}$, Agada Samson Arome ${ }^{2}$ \\ ${ }^{1}$ benue State University Makurdi \\ ${ }^{2}$ chief Librarian Kogi State College Of Education Ankpa
}

\begin{abstract}
The present study investigated information dissemination as a tool for curbing the twin cultural practices of wife inheritance and polygamy in Benue state of Nigeria. A total number of 4500 participants ( 2250 men and 2250 women) were drawn in equal number from each of the three senatorial zones in the state for the study. Using a structured questionnaire and simple random sampling techniques, data were collected and analyzed. Independent t-test statistics was used to test the study hypothesis. The result revealed that, (1) there was no significant difference in the perceptions of men and women on polygamous marriages as a mode of Hiv/aids transmission in the state. (ii) There was a significant difference between men and women on the perception of wife inheritance as a mode of Hiv transmission in the state with the men being more aware of the practice of wife inheritance in this regard than the women. It was suggested that, library and information practitioners, having the responsibility of information dissemination, storage and retrieval must go beyond the walls of the library to expose to the average Benue woman the dangers behind these cultural practices, that women should be more proactive to empowering their selves than depending solely on the men. While this is done, it is expected that these cultural practices will gradually go into extinct.
\end{abstract}

\section{Introduction}

Culture is an important aspect of human life; hence every tribe or ethnic group has cultural practices. Such cultural practices may have merits and demerits, given the present scientific studies carried out in relation to these cultural practices. Apart from the scientific findings on some cultural practices, Human Right Organization objects to some practices that seem to project inequality between men and women, boys and girls.

Traditional practices have become a matter of concern to the international community especially as it affects the status and human rights of women and female children. The transformed slogan "Woman Right and Human Right" adopted at the world conference on human rights in Vienna in 1993 and the Declaration on the elimination of all forms of violence against women as was equally adopted by the general Assembly same year tallied with the status accorded to women. This was adopted in recognition of the need to eliminate some cultural practices that do not promote inequality only but are harmful to the women and the entire humanity.

From the forgoing it is clear that the rights of the women and children is established and protected. But that does not mean enforcement. Hence, the continuous practice polygamy and wife inheritance among other cultures in Benue State. Most women who are victims of wife inheritance after the death of a husband are not fully and adequately informed of the negative consequences of that either as a result of illiteracy or poverty.

They feel that it is better for them to be inherited by a deceased husband's younger brother or relation and have his protection than to be tossed about after the demise of a husband. Information available to them at that time and in most cases limits them to finding refuge under a diseased husband's relation irrespective or his health status. This is why it is good for every woman to be properly informed of the dangers and consequences of polygamy and wife inheritance.

Until the advent of Christianity and colonialism in Nigeria, polygamy was regarded as a fair and right culture. A man has the right to marry as many wives as possible and father also many children as possible.

Several reasons were responsible for this, and ( Niger 2012) explained three reason why man generally practice polygamy and these are; "scarcity of adult male, some males may have much better genes than others which is particularly important in population where there is heavy load of diseases and parasites to which resistance is genetically heritable. Third, females do better by sharing a mate who defends a good territory (with plenty of food and cover) than they would by opting to be a single mate in a bad territory". Among the Tiv people of North-central Nigeria, polygamy was accepted because the people are predominantly farmers involved in non-mechanized farming up till today. So the number of wives determines the number and children, by implication means more free hands to work on the farm thereby, more produce to the barns. This makes the man wealthier, because at the end of each harvest season, the wives are expected to submit everything they have harvested to the man, because traditionally the woman has little or no access to and control over resources. The second is the war theory:- it was believed that because men go to war and are killed in the process, there are 
more women to fewer men so a man can marry as many as possible to make up for the gap. In Nigeria, polygamy is a culturally accepted and socially respected institution.

Even though the federal Government of Nigeria have not legally recognized polygamy, Northern states of Bauchi, Borno, Kebbi, Jigawa, Kano, Kaduna, Sokoto Katsina,Zamfara, Gombe, Yobe,and Niger have all recognized polygamous marriages under sharia ( Islamic law) which permits a man to marry up to four wives provided he can meet the same level of love and care to all of them. The southern part of Nigeria is made up of mostly Christians, as such have not legally introduced polygamous marriages. However, it is recognized nationwide by customary law. As at 2009 the federal government had not made polygamous marriages a civil right, but the legislation is played out with on a state by state level according to the predominant religion in the various states of the country.

Information according to( Ozioko 2007,Laloo 2002, and Chen and Hemon 1982) is any stimulus that reduces uncertainty" and all knowledge, ideas, facts, data, and imaginative works of mind which are communicated formally and/ or informally in any format". (Uwen, 1993) in Ozioko (2007) defined information as data that have been subjected to some processing functions capable of answering a user's query, be it recorded, summarized or simply collected that would help decision making. Therefore, it is pertinent to say that the presence of information creates options, sets the stage for meaningful decision- making and alternative approaches to solving problems are examined for final decisions. Information constitutes the raw materials for which options or alternative emerge. Benue state being an agrarian state, a greater number of the populace are illiterates and so ill-informed and need information to solve their problem of harmful cultural practices especially of polygamy and wife inheritance. Attention is draw to these two practices because of the tendency to spread sexually transmitted infection and especially the dreaded HIV/Aids infection which according to (BENSACA2012) Benue state has contributed 6.7\% (192.400 HIV positive population of the world).

Information needs on the other hand means an imbalance existing between what a person knows and what the person is supposed to know. In order words, there is a gap existing between the present situation and the more desirable situation. At the personal level, we need a great deal of information to make spectacular changes and progress in our daily activities of life.

Information empowers and propels people into self actualization. Therefore information provides the leverage required for the economic and social empowerment of women. (Medel- Anonuevo 1997) stated that the goals of women empowerment include to challenge and transform the ideology and practice of women's subordination, to transform the structure and institutions which have upheld and reinforced this ethnicity, and the social, economic and political structures and institutions including region, education systems, the media, the law, top-down development models e.t.c, to gain access and control over materials and knowledge resources.

Apart from the subordination factor, the twin cultural practices of wife inheritance and polygamy are strong and viable agents of HIV/AIDS. Which Sudha-Salham (2003) reports that black women have a desperately increased infection rate. At this juncture I pose to ask why black women have a desperately increased infection rate. The answer is either because they don't have control over their bodies as African culture looks at women as men's property or because of ill-information on what is right for them. The HIV/AIDS scourge has taken a global toll on human societies, the variations among regions and nations being that of degree or extent. There is now no country of the world where the infection has not made an incursion since the first case of AIDS was diagnosed in 1981, the world has struggled to conue grips with its extraordinary dimensions. According to the global estimates of HIV and AIDS as of end of 2003, a total of 37.8 million were admits aged 15 years and above. Women made up 17 million people were living with HIV, among them, 3.7million while, 2.1million were children less than 15 years (UNAIDS, 2004) within this estimated figures, sub-Saharan African, of which Nigerian is a part, bore the unenviable burden of 25 million. In the third decade of the global epidemic Nigeria has contributed significantly to its prevalence worldwide.

After the first case was diagnosed in the country in 1986, the national prevalence rose from $1.8 \%$ in 1991 to $5.8 \%$ in 2001, slightly dropped to $4.4 \%$ in 2005 and rose to $4.6 \%$ in 2008 (ANC Survey 2008).Focusing on Benue State, studies have shown that the trend in prevalence rates was $1.8 \%$ in $1991,5.8 \%$ in 2001 , to $10 \%$ in 2005 but rose to $10.6 \%$ in 2008 (BENSACA 2012). These estimates suggest that Benue State contributes about $6.7 \%$ (192,400 HIV positive populations) of the burden of HIV infection of the country although the state is only about $3 \%$ of the national population. Modes of HIV transmission have been enumerated as heterosexual intercourse with an infected partner, blood and blood product transfusion of an infected person, inject able drug users (IDUS), men who sleep with men (MSM), unprotected sex with female sex workers (FSW) and transmission through sharing of unsterilized sharp objects. Other mode (ANC 2008) includes wife inheritance, polygamous marriage which is akin to multiple sex partnerships. While many of the practices that serve as modes of HIV transmission are frowned at by society and are even morally sanctioned e.g. sex work and homosexuality and to some extent, inject able drug users other practices that serve as modes in cultural practices that are seen not just as normal but as cultural obligation that must be obeyed and even encouraged. Examples of such practices are wife inheritance and polygamous marriage which still strive in the Benue society especially 
among the less educated and rural dwellers. The presents study investigated the perceptions of men and women regarding the twin cultural practices of wife inheritance and polygamous marriage as modes of HIV transmission in the state. The two hypotheses tested were the following: (i) Males and females do not differ on their perception of polygamous marriages as modes of HIV transmission.(ii) Men and women do not differ in their perception over wife inheritance as a significant mode of HIV transmission.

\section{Design of study:}

\section{Methodology}

The study adopted the survey design for its economy for data collection in a relatively large population considered in this study moreover, since opinions, perceptions and views of samples from this population was going to be studied, the survey method was considered a suitable design choice.

\section{Sample/Sampling Technique}

The population of Benue state of Nigeria from where the sample was taken is about 4.5 million (NPC 2006) cluster sampling was used to select three local government areas each from each of the geographical zones. From each Local government area, simple random sampling technique was used to select equal number of male female participant in this manner: Katsina-Ala, Ukum and Kwande Local government areas were selected from Zone "A" Gboko, Makurdi and Guma from Zone "B", while Otukpo, Agatu and Ohimini were chosen from Zone "C"From each of the local government area 250 male and 250 female participants were selected making a total sample size if 4500 , about $10 \%$ of the entire population.

\section{Instrumentation}

A structural questionnaire titled "cultural practices and the spread of HIV/AIDS questionnaire (CPSHAQ) was used for data collection. The question naira was self developed was potted into two parts section A, which sought demographic data on participants' contains 6 items section B contains 8 items. The items in section B were formulated in liker scale format. Each item statement was followed by five options. The options were "Strongly Agree (SA) "Agree" (A) Undecided (U) Disagree (D) and "Strongly Disagree" (SD). Each option was given a numeric weight that corresponds to the strength of agreement with the statement. Ion this way, $\mathrm{SA}$ was assigned $5, \mathrm{~A}=4, \mathrm{u}=3, \mathrm{D}=2$ and $\mathrm{SD}=1$. If a statement was worded in the opposite direction the scores were reversed. A sample item from the questionnaire, is 'polygamous marriage system promotes the spread of HIV/AIDS sum of scores on the questionnaire could range from 8 to 40 per participant. A pilot study using a sample of 1500 participants, employing the test retest reliability method yielded a reliability coefficient of 0.75 cronbach's alpha over a 4 weeks interval.

\section{Procedure}

Question naira was administrated face to face on respondents by the researcher or her trained research assistants. Participants were approached at the market places, church premises at the college of education, katsina-Ala premises or at their homes wherever this was appropriate for a particular zone. Informed consents were obtained orally from participants. They were informed that participation is voluntary they were also assured of the confidentiality of the information they would provide. For participants who could not read or write, the statements from the questionnaire were read out to them and their responses were filled in by the researcher or her assistants. Method of data analysis the research hypotheses were tested using the independent samples t-test.

\section{Results}

Two hypotheses were stated and tested in this study. The first hypothesis was that male and female participants do not differ significantly on their perception that polygamous marriages are a mode of the test of this hypothesis, using the independent samples t-test is presented in table 1.Table1: Independent t-test scores of the difference in perception between male and female participants on polygamous marriages as mode of HIV transmission in Benue state.

Variables

\begin{tabular}{|l|l|l|l|l|l|l|}
\hline \multicolumn{1}{|c|}{ Sex } & $\mathrm{N}$ & Mean & Df & $\mathrm{t}(\mathrm{cal})$ & $\mathrm{t}(\mathrm{ant})$ & Decision \\
\hline Male & 2250 & 3.981 & 4498 & 1.21 & 1.96 & Upheld \\
\hline female & 2250 & 2.62 & & & & \\
& & & & & & \\
\hline
\end{tabular}

Polygamous marriage (d.v) 
The result from Table1 shows that the calculation t-value of 1.21 is less than the critical (table) value of 1.96 at degree of freedom 4498 both checked at the 0.05 level of significance. The null hypothesis was upheld which states that men and women do not differ in perception that polygamous marriages is a mode of HIV transmission in Benue State. This means that men and women have the same view that polygamous marriage is not a significant driver in the spread of HIV in Benue Sate. The second hypothesis tested was that men and women do not differ significantly on the perception that wife inheritance is mode of HIV transmission. The result of the test of this hypothesis using independent t-test is presented in table 2. Table 2: Independent samples $\mathrm{t}$-test scores on the difference between men and women on the perception that wife inheritance is a mode of HIV transmission.

Variables

\begin{tabular}{|c|l|l|l|l|l|l|}
\hline Sex & $\mathrm{N}$ & Mean & $\mathrm{dt}$ & $\mathrm{t}(\mathrm{cal})$ & $\mathrm{t}$ (crit) & Decision \\
\hline Male & 2250 & 3.08 & 4498 & 5.30 & 7.05 & Reject \\
\hline Female & 2250 & 2.04 & & & & tHO \\
\hline
\end{tabular}

The result in table 2 indicates that the calculate t-value of 5.30 at degrees of freedom of 4498 is higher that the critical value of 1.05 at the same degrees of freedom both checked at that 0.05 level of significance. The null hypothesis is hence rejected and the alternate hypothesis that men differ significantly from women on the perception that wife inheritance is a mode of HIV transmission in Benue state.

\section{Discussion}

The present study investigated the perceptions or men and women on the cultural practices of polygamous marriages and wife inheritances as modes of HIV transmission in Benue state. On of the findings suggests that men did not differ from the women on the perception that polygamous marriages encourage the spread of HIV among the Benue state populace. The implications of this finding could suggest that both men and women are in agreement about polygamous marriages. This endorsement might be due to the pervasive influence of culture among the people and that there is high conformity to the culture by the sample of the respondents. The fact that men have a higher mean score than the women suggests that men perceive the culture more risky in the spread of HIV than women but they (men) still persists in the practice. This implies that the cultural pull toward polygamous marriages is much stronger than the individuals' perceptions about its dangers.

The findings of the second hypothesis that men differed significantly from women on the perception that wife inheritance is significant suggests that men perceive this danger more than women as indicated by the formers higher mean score (3.08). This implies that men may be less willing now than before to succumb to this cultural practice. However, where this still persists, the men are possibly being pressured into the practice in conformity to cultural demands. The findings that women lower mean score on perception of this practice compared to men could be the fear of social adverse consequences they appear to be going against the cultural practice. It is also possible that the economic and other social benefits the women stand to gain in conforming to the cultural demand far outweigh the rejection for it. In both cases for men and women, this implication for the spread of HIV through this practice and mode might be sustained in the state.

\section{Summary And Implications For Library Information Secientist.}

According to (Yahya 2009), the success of rural information programmes rests on the availability and use of quality information by rural development workers and rural people and that many rural development programmes have failed in developing countries because they were planned with insufficient relevant information. This explains the non differing views of men and women regarding the culture practice of polygamous marriages as a factor in the spread of HV/AIDS in Benue state suggesting that, both sex categories are aware of the danger this practices portends in sustaining the spread of the infection. The continued acceptance and practice of polygamous marriages vis-à-vis the danger of HIV/AIDS transmission among practitioners may depend on the strength of the cultural pull and other relevant factors. Conversely, the study tends to suggest that men, perceive the danger of wife inheritance as a source of HIV/AIDS transmission more than the women. The implication is that ignoring cultural pressure in the face of the danger of HIV/AIDS infection, this cultural practice might become extinct in the near future in the state.

The role of library information disseminators in all of these is to document these jewel of information in ways that they can be available accessible and easily retrievable by the public. This can be informing of fact sheets, in both hard and soft copies. Information services Ape (2012 explains that are carried out in order to spread the authentic news to members of the society about current changes for proper decision-making and societal well being. This is making available new knowledge or ideas known to members of the society so as to enable them improve their condition of living as well as develop their environment. Therefore it is hope that giving information about the danger of wife inheritance and polygamy can help to curb the harmful practice. 
As information professional, disseminations of value added information is our major pre- occupation. In other to achieve this, librarians can work in partnership with other professional bodies like Federation of Female Lawyers in Nigeria (FIDA) women and child rights organization, religious body to pass necessary information out to the average Benue woman to let them know of the danger associated with these practices and how to cleverly run away from them. Information can be disseminated through various channels, formats and levels to women who are sub-due and marginalized due to their environment and culture.

In addition to the creation of awareness to women, children's library services can be used to properly inform the Benue child on the dangers of harmful cultural practices at an early stage in life so that it can stick to the their brain and grow with them. This can help in no small measure to curb these practices.

\section{References}

[1]. Asa, U.J (2006) Curbing Traditional Practices for the removal of the Risk of HIV/AIDS and other communicable disease. A paper presented at a seminar on "The effect of human trafficking and violence Against women and youths in the society" organized by the ministry for local government and Chieftaincy affairs in conjunction with touch consultants held at the conference hall of Our Lady of Perpetual Help Cathedral, Makurdi.

[2]. Ape, R (2012) meeting Health information needs of people with HIV/AIDS through public library services in Benue state. A PhD thesis; University of Nigeria, Nsukka.

[3]. Benue State Agency for the Control of HIV /AIDS (2008). HIV/AIDS modes of transmission in Benue State. Makurdi BENSACA Ante-Natal Care survey (2005). National HIV/Syphihis. Abuja Federal Ministry of Health

[4]. Medel-anonuevo, O. (1997) Learning Gender Justice, the challenge for Adult Education in the $21^{\text {st }}$ century. Journal of Adult Education and Development 49,81-90.

[5]. National POPULATION commission (2006). National Demographic and population census. Abuja national population commission.

[6]. Niger, B. (2012) The three reasons for polygamy. In, the human beast.www.psychologytoday.com/blog/the human beast/201210/the-three-reason-polygamy. Retrieved 26/04/13.

[7]. Omanze,O.U. and Ibene,S.K.(2011) obstacles to provision and use of development information in rural communities in Nigeria. Library Philosophy and Practice. http://.www.uidaho.edu/-mbolin/lpp.html. retrieved 23/04.13.

[8]. Sudha,S (2003). women and HIV/AIDS. New Delhi; Jaypee Brothers Medical Publishers Limited.

[9]. UNAIDS (2004) Report on the global AIDS Epidemic. Geneva: UNAIDS.

[10]. Yahya, ,I.H. (2009). Information Services for Rural Community Development. Library Philosophy and Practice. http://.www.uidaho.edu/-mbolin/lpp.html. retrieved 23/04.13. 